\title{
EKSISTENSI KESENIAN BARONGAN SETYO BUDOYO DI DESA LORAM WETAN KECAMATAN JATI KABUPATEN KUDUS
}

\author{
Dinda Putri Ayuningtyas \\ Fakultas Bahasa dan Seni, Universitas Negeri Yogyakarta \\ E-mail: dindaputri_ayuningtyas@yahoo.com
}

\begin{abstract}
Abstrak
Tujuan penelitian ini adalah untuk mendeskripsikan eksistensi kesenian Barongan Setyo Budoyo di Desa Loram Wetan Kecamatan Jati Kabupaten Kudus. Penelitian ini menggunakan pendekatan kualitatif deskriptif. Objek penelitian ini adalah kesenian Barongan Kudus. Subjek penelitian ini adalah ketua kesenian barongan Setyo Budoyo,penari barongan, dinas kebudayaan dan pariwisata, serta perangkat desa Loram Wetan. Pengumpulan data dalam penelitian ini menggunakan teknik: observasi, wawancara, dan dokumentasi. Adapun teknik analisis data ini yaitu reduksi data, penyajian data, dan pengambilan kesimpulan. Teknik Keabsahan Data menggunakan triangulasi. Hasil penelitian ini adalah sebagai berikut:1) Sejarah kesenian Barongan Kudus yang diambil dari cerita babat tanah Jawa; 2) Bentuk penyajian Kesenian Barongan Setyo Budoyo yaitu gerak, tata rias, tata busana, tempat pementasan/pertunjukan, properti, iringan musik; 3) Bentuk pelestarian Kesenian Barongan yaitu melestarikan kesenian barongan yang dibutuhkan adanya kerjasama anatara pelaku kesenian dengan pemerintah terkait untuk melestarikan kesenian barongan Setyo Budoyo yang hampir punah.
\end{abstract}

Kata kunci: eksistensi, kesenian, barongan

\section{THE EXISTENCE OF SETYO BUDOYO BARONGAN ARTS IN LORAM WETAN VILLAGE, JATI DISTRICTS, KUDUS REGENCY}

\begin{abstract}
s
The aim of this research is to describe the existence of Setyo Budoyo Barongan Arts in Loram Wetan Village, Jati Districts, Kudus Regency.This research is using qualitative descriptive approach. Object of this research is Barongan Arts in Kudus. Subjects of this research are the leader of Setyo Budoyo Barongan Arts, Barongan dancer, culture and tourism official, also the employee of Loram Wetan Village. Data collection on this research using observation, interview and documentation techniques. While data analysis by data reduction, data presentation and taking conclusion. Data validity techniques by triangulation. The results of this research are: 1) The history of Barongan Kudus was taken from Babat Tanah Jawa story; 2) The presentation form of Setyo Budoyo Barongan Arts are movement, make up, costume, stage, property, and accompaniment; 3) The preservation form of Barongan Arts is conserve it, and it needs the cooperation between the artists and the government to conserve Setyo Budoyo Barongan Arts that almost extinct.
\end{abstract}

Keywords: existence, arts, barongan 


\section{PENDAHULUAN}

Kudus merupakan kabupaten paling sempit di Provinsi Jawa Tengah dengan 9 kecamatan. Meskipun luas wilayahnya sempit tetapi terdapat bangunan-bangunan perusahaan ternama. Kudus juga memiliki berbagai kebudayaan selain tari kretek yang sudah terkenal dan juga memiliki kesenian tradisi yang bernama kesenian Barongan. Barongan adalah salah satu kesenian khas Jawa Tengah. Barongan adalah karakter dalam mitologi Jawa dan akulturasi Bali. Barongan dilukiskan sebagai raja dari roh-roh serta melambangkan kebaikan atau pelindung. Sebagai pelindung barongan ditampilkan dalam wujud singa.

Seiring dengan perkembangan zaman hingga sekarang dalam kesenian tradisional mengalami penurunan minat dan eksistensi, pada zaman dahulu kesenian Barongan sering dipertunjukan dalam setiap acara karena kesenian Barongan sudah menjadi tradisi untuk masyarakat setempat. Dalam upacara ruwatan masyarakat sering menggunakan kesenian Barongan sebagai tolak balak serta acara hajatan seperti khitanan. Bahkan peringatan hari-hari nasional sering menampilkan kesenian Barongan sebagai hiburan atau tontonan masyarakat. Dengan demikian kesenian Barongan pada jaman itu, masyarakat antusias untuk melestarikan kesenian Barongan. Berbeda dengan pada zaman sekarang, kesenian Barongan sudah jarang dipertunjukan untuk acara ruwatan serta hajatan. Sekarang ini kesenian Barongan kurang di minatimasyarakat bahkan hampir ditingglkan. Dahulu dalam penyajian penampilan masih diisi dengan tokoh yang lengkap tetapi sekarang ini hanya diisi tokoh Singo Barong, Penthul, dan penari jaran kepang bahkan adegan magis sekarang ini ditinggalkan.

Dalam penyajian kesenian Barongan masih bersifat monoton dan belum ada perkembangan dalam gerakannya sehingga kesenian tersebuat tidak menarik untuk ditonton. Sekarang ini dalam perkembangan gerakannya hanya dilakukan oleh tokoh Penthul, Singo Barong, dan penari jaran kepang yang dilakukan dengan gerakan improvisasi yang disesuaikan dengan iringan musik.
Pengertian eksistensi menurut Zainal Abidin (2007: 16) adalah tidak bersifat kaku dan terhenti, melainkan lentur dan mengalami perkembangan atau sebaliknya kemunduran, tergantung pada kemampuan individu dalam mengaktualisasikan potensi-potensinya. Dalam bentuk penyajian menurut Langer (1988: 15) bentuk adalah struktur artikulasi sebuah hasil kesatuan yang menyeluruh dari satu hubungan berbagai faktor yang terkait. Istilah penyajian dapat didefinisikan cara penyajian, proses, pengaturan, dan penampilan dalam satu pementasan, karena dalam pementasan meliputi gerak, musik, tata rias dan busana, tempat pertunjukan, serta properti. Adapun bentuk penyajian sebagai berikut:

a. Gerak

Menurut Jazuli (1994: 5) hasil dari proses pengolahan yang telah mengalami stilasi (digayakan) dan distorsi (pengubahan) yang kemudian melahirkan dua jenis gerak yaitu gerak murni dan gerak maknawi.

b. Tata rias

Menurut Jazuli (1994: 18) tata rias adalah tampilan pertama yang dilihat oleh penonton sebelum pertunjukan dimulai dengan mengubah karakter pribadi menjadi karakter tokoh yang diperlukan, untuk memperkuat ekspresi dan menambah daya tarik penari pada penampilannya.

c. Tata busana

Menurut Jazuli (2008: 20) berpendapat bahwa fungsi busana tari adalah untuk mendukung tema atau isi tari, dan untuk memperjelas peran-peran dalam suatu sajian tari.

d. Tempat Pementasan

Menurut Jazuli (1994: 20) berpendapat tempat pentas suatu pertunjukan apa pun bentuknya selalu memerlukan tempat atau ruangan guna menyelenggarakan pertunjukan itu sendiri.

e. Properti

Menurut Kusmayanti (2000: 96) mengungkapkan properti juga berfungsi sebagai sesaji bukan hanya benda-benda atau barang-barang yang dipersembahkan 
dan sesudahnya dapat disantap bersama komunitas sebuah pertunjukan.

f. Iringan musik

Menurut Jazuli (1994: 9-12) berpendapat musik atau suara dalam tari pada dasarnya dibedakan menjadi dua bentuk yaitu bentuk internal dan bentuk eksternal.

g. Pola lantai

Menurut Soedarsono (1978: 2) pola lantai dasar dibagai menjadi dua bagian, diantaranya adalah pola lantai garis lurus dan pola garis lantai lengkung.

Pengertian pelestarian menurut Jacobus (2006: 115) adalah sebagai kegiatan atau yang dilakukan secara terus menerus, terarah dan terpadu guna mewujudkan tujuan tertentu yang mencerminkan adanya sesuatu yang tetap dan abadi, bersifat dinamis, luwes, dan selektif. Pengertian kesenian menurut Sedyawati (1981: 61) mengungkapkan bahwa kesenian memiliki banyak peranan penting di masyarakat dan peranan itu di tentukan oleh keadaan masyarakatnya.

Pengertian barongan menurut $S$ Dwidjo Sumono (1993:4) adalah dalam arti sebenarnya adalah simbol atau gambaran dari pengejawantahan si raja hutan yang besar yaitu simbol Singo Barong atau Macan Gembong. Pengertian sejarah menurut Kartodirjo (1982: 12) adalah gambaran tentang masa lalu tentang manusia dan sekitarnya sebagai makhluk sosial yang disusun secara ilmiah dan lengkap, meliputi urutan fakta masa tersebut dengan tafsiran dan penjelasan yang memberikan pengertian tentang apa yang telah berlalu.

\section{PEMBAHASAN}

Sejarah kesenian Barongan sampai sekarang belum diketahui secara pasti karena data yang tertulis sampai sekarang belum di ketahui. Tetapi kesenian Barongan mulai ada di tanah air Pulau Jawa sejak tahun 1915. Kesenian Barongan Kudus berkembang sejak Ki Gede Loram berkuasa dan didukung oleh Ki Gede Getas menjadikan kesenian Barongan lebih maju dan berkembang. Pada awal perkembangan kesenian Barongan digunakan untuk berdakwah, pendidikan masyarakat untuk sajian tontonan kesenian ini. Kesenian Barongan Kudus mengambil cerita dari Babat Tanah Jawa, Kesenian Barongan Setyo Budoyo diketuai oleh Bapak Nanang Sukadi dan beranggotakan 28 orang. Berdirinya kesenian Barongan Setyo Budoyo pada tanggal 1 Februari 1994. Bentuk penyajian kesenian barongan Kudus hanya dilakukan oleh tokoh Penthul, Singo Barong, dan pemain jaran kepang adalah sebagai berikut:

a. Gerak tari

1. Gerakan ulap adalah gerakan yang digunakan Tokoh Penthul pada babak pertama biasanya saat menari bersama dengan Singo Barong dan pemain Kuda Kepang.

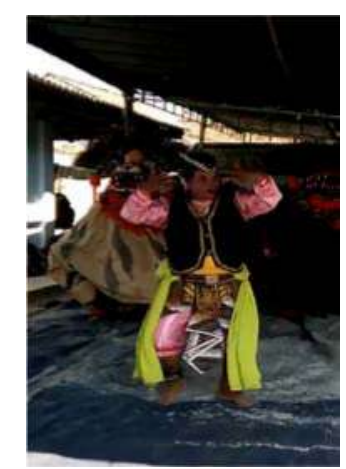

Gambar 1. Gerakan Ulap-Ulap tokoh Penthul ( Foto: Dinda, 2017)

2. Gerakan Miwir Sampur adalah gerakan yang selalu dipakai tokoh Penthul saat melakukan pergantian gerakan maupun penyerangan terhadap Singo Barong pada adegan pertama.

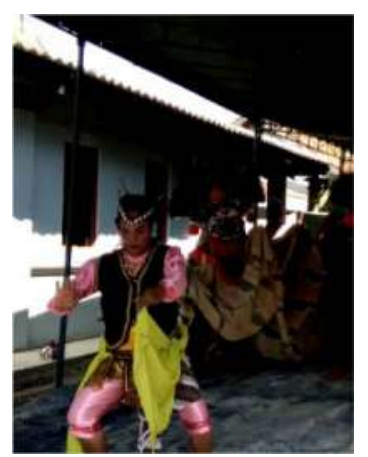

Gambar 2. Gerakan Miwir Sampur tokoh Penthul (Foto: Dinda, 2017) 
3. Gerakan Egolan adalah gerakan yang digunakan untuk mengejek Singo Barong saat akan melakukan peperangan melawan Singo Barong.

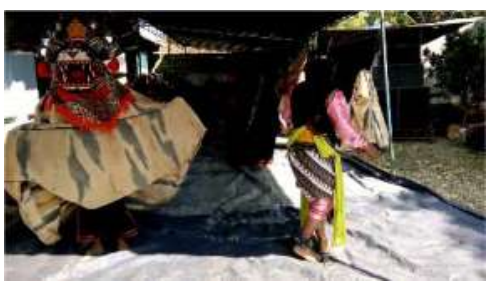

Gambar 3. Egolan pada tokoh Penthul (Foto: Dinda, 2017)

4. Gerakan Lembehan adalah gerakan yang dilakukan oleh tokoh Penthul untuk perpindahan posisi atau tempat sehingga bisa berhadapan dengan Singo Barong.

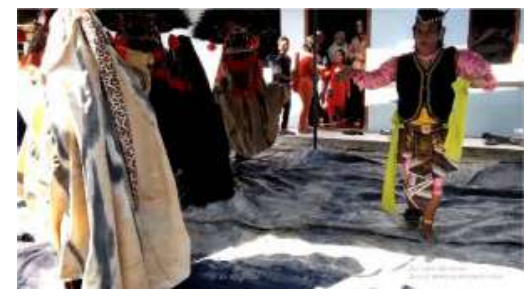

Gambar 4. Gerakan Lembehan tokoh Penthul (Foto: Dinda, 2017)

5. Gerakan Pancalan merupakan gerakan silat untuk melakukan perlawanan terhadap Singo Barong sebagai perlawanan diri.

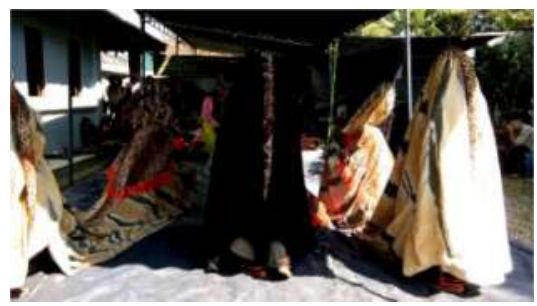

Gambar 5. Gerakan Pancalan (Foto: Dinda, 2017)

2. Gerakan tari Singo Barong

a) Ngaklak adalah menjadi ciri khas dari suara Barong, yaitu gerakan membuka tutup mulut Barong dengan lebar, cepat dan berulang sehingga menghasilkan bunyi "klak-klak" dan dilakukan pada posisi kepala Barong menghadap atas hingga bawah. Gerakan ngaklak dilakukan oleh pembarong yang bermakna kekuatan yang dimiliki.

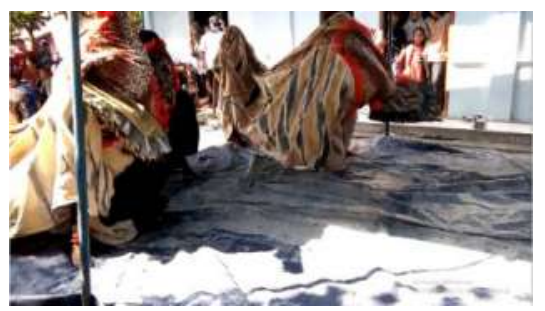

Gambar 6. Gerakan Ngaklak Singo Barong (Foto: Dinda, 2017)

b) Caplokan adalah memiliki pengertian yang hampir sama dengan ngaklak. Yaitu membuka lebar kemudian menutup mulut Barongan, namun pada caplokan tidak terjadi pengulangan gerak.

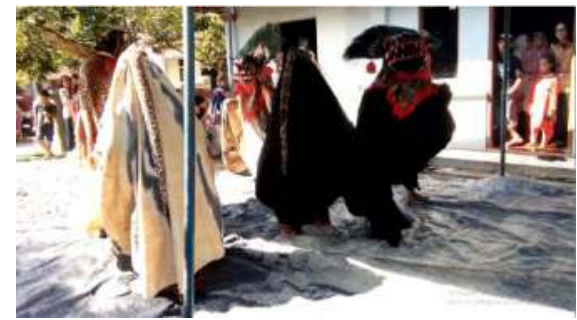

Gambar 7. Gerakan Caplokan Singo Barong (Foto: Dinda, 2017)

c) Ndekem atau biasa disebut dengan dekeman adalah gerakan Barongan pada level rendah dalam sebuah tarian. Dekeman merupakan posisi di mana kepala dan badan barong menempel pada lantai. Gerakan dekeman dapat dilihat pada akhir pertunjukan inti kesenian Barongan karena dekeman menjadi pertanda sang Barong telah menyerah kalah oleh serangan Penthul.

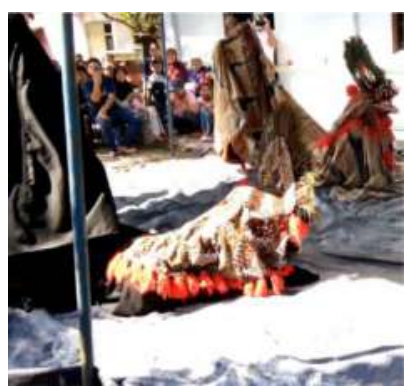

Gambar 8. Gerakan Ndekem Singo Barong (Foto: Dinda, 2017) 
d) Glundungan adalah gerakan menjatuhkan badan ke arah belakang, kanan atau ke kiri yang dilakukan Barongan pada saat mendapat tendangan dari Penthul. Glundungan membutuhkan kekompakan dari pemain yang berperan menjadi kepala barong dan ekor barong karena apabila kepala barong menjatuhkan badan ke arah kanan atau sebaliknya, maka ekor barong juga harus mengikuti dengan gerakan yang sama.

\section{c. Tata Rias}

Tata rias dalam pemain seni barong untuk menarik penonton terutama pada tokoh Penthul dan jaran kepang menggunakan riasan panggung sedangkan tokoh Tembem, Bondet, Celeng, Gandarwa, dan Singo Barong tidak memerlukan rias wajah karena tokoh tersebut menggunakan topeng yang disesuaikan karakter mereka.

\section{d. Tata Busana/Kostum}

Kostum yang dipakai pemin seni Barongan sebagai berikut:

1) Tokoh Penthul menggunakan kostum berupa baju lengan panjang yang mencolok biasanya waran biru atau merah muda, celana tiga perempat menyesuaikan dengan baju yang dipakai (biru atau merah muda), jarik yang bentuk sapit urang, ikat pinggang warna hitam, boro samir, sampur serta dilengkapi dengan dengan keris, kalung, kerincingan, dan ikat kepala yang berwarna hitam.

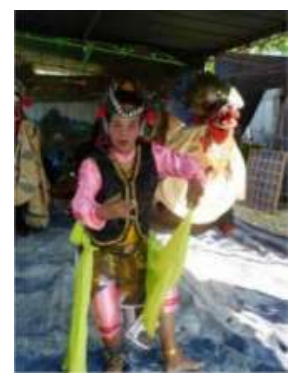

Gambar 9. Kostum Tokoh Penthul (Foto: Dinda, 2017)
2) Tokoh Gendarwa belum memiliki ketentuan dalam kostum menyesuaikan dengan kostum yang dipakai pemain biasanya tokoh Gendarwa memakai baju hitam dan celana hitam yang melambangkan kejahatan.

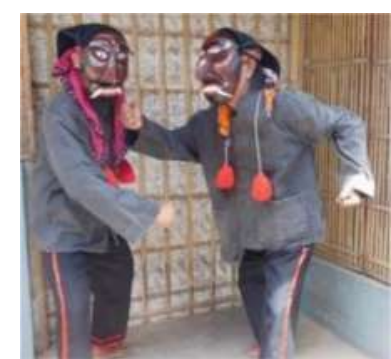

Gambar 10. Kostum Gendarwa (Foto: Dinda, 2017)

3) Pemain Jaran Kepang dibagi 2 yaitu pemain jaran kepang putri dan pemain jaran kepang putra. Kostum pemain jaran kepang putriberupa kebayayang mencolok, jarik, celana tiga perempat, stagen, kalung atau bros, dan ikat kepala sedagkan pemain jaran kepang putra berupa rompi, jarik sapit urang, celana tiga perempat, sabuk, stagen, ikat kepala, gelang, kelat bahu.

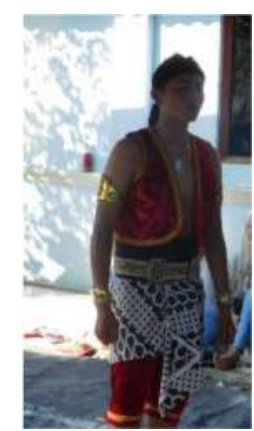

Gambar 11. Kostum Pemain Jaran Kepang (Putra)

(Foto: Dinda, 2017)

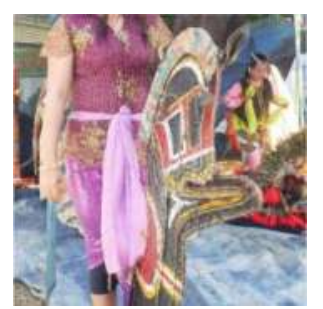

Gambar 12. Kostum Pemain Jaran Kepang (Putri)

(Foto: Dinda, 2017) 
e. Tempat Pementasan dalam pemetasan kesenian Barongan dibutuhkan tempat yang luas seperti lapangan, halaman dan sebagainya karena jumlah pemain yang terlalu banyak memerlukan tempat yang luas.

\section{f. Properti}

Properti dapatberfungsi sebagai pendukung tema atau isi tari. Properti dalam kesenian Barongan adalah sebagai berikut:

1. Topeng Barong

Topeng Barong yang digunakan untuk pementasan kesenian Barongan Setyo Budoyo ada 3 macam. Topeng barong dalam kesenian barongan Setyo Budoyo merupakan pemeran utama. Kepala Macan Barong terbuat dari kayu pohon Mahoni, di bagian atas terdapat hiasan dari bulu merak. Untuk bagian badan Barongan dipasang kain lebar dan panjang bermotif loreng hitam dan kuning dan memiliki ekor, biasanya ada 2 pemain yang masuk di dalam kostum barongan.

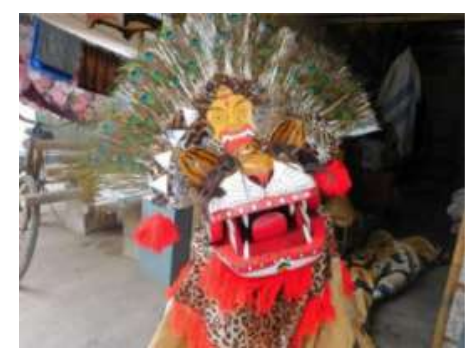

Gambar 13. Singo Barong (Foto: Dinda, 2018)

\section{Topeng Bondet}

Kepala Bondet terbuat dari kayu yang membentuk kepala anjing, dan badan terbuat dari kain berwarna loreng dan di beri lubang untuk melihat keadaan diluar sedangkan kepala bondet di pegang dengan tangan pemainnya.

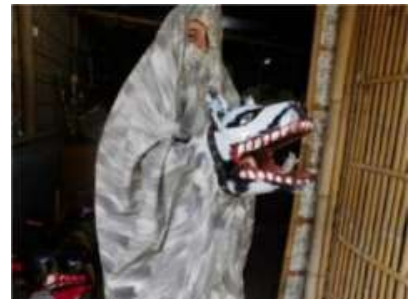

Gambar 14. Topeng Bondet (Foto: Dinda, 2018)

\section{Topeng Celeng}

Kepala Celeng terbuat dari kayu yang membentuk kepala babi hutan, dan badan terbuat dari kain goni berwarana loreng dan di beri lubang untuk melihat keadaan diluar sedangkan kepala celeng di pegang dengan tangan pemainnya

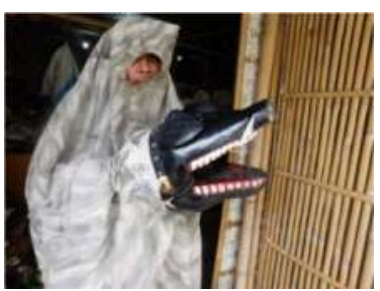

Gambar 15. Topeng Celeng (Foto: Dinda, 2018)

\section{Topeng Penthul}

Topeng Penthul terbuat dari kayu yang didesain dengan wajah yang lucu agar menarik penonton, sebenarnya topeng ini hanya dipakai untuk hiasan kepala saja dan tidak untuk dimainkan.

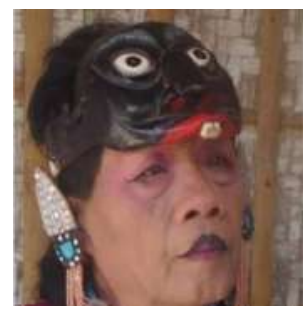

Gambar 16. Topeng Penthul (Foto: Dinda, 2018)

\section{Topeng Gendarwa}

Topeng Gendarwa digambarkan sebagai tokoh jahat dan sering mengganggu tokohtokoh lainnya. 


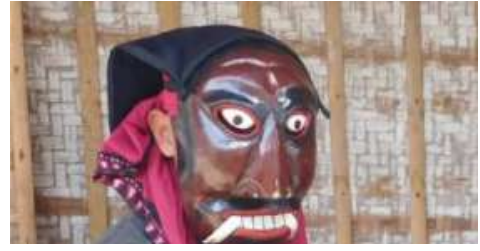

Gambar 17. Topeng Gendarwa (Foto: Dinda, 2018)

\section{Jaran Kepang}

Jaran Kepang merupakan salah satu properti dalam pementasan seni Barong Kudus yang terbuat dari anyaman bambu yang memiliki kualitas baik agar lebih awet dalam pemakaian.

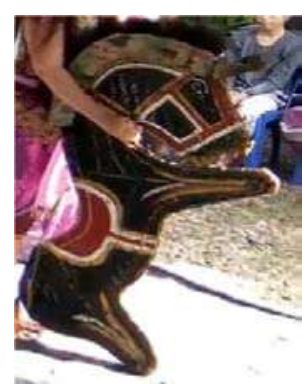

Gambar 18. Kuda Kepang (Foto: Dinda, 2018)

\section{Pecut}

Pecut digunakan untuk mencambuki pemain jaran kepang yag sudah dibacakan matra oleh pawing sehingga pemain jaran kepang tidak merasakan sakit.

\section{Kerincingan}

Kerincingan atau lonceng yang dipakai oleh tokoh Penthul di pergelangan kaki kanan dengan tujuan menimbulkan bunyi saat menghentakkan kakinya dan membuat suasana ramai.

\section{Sampur}

Sampur yang dipakai oleh tokoh Penthul selalu digunakan saat menari pada babak pertama maupun saat perang dengan Singo Barong.

\section{g. Iringan Musik}

Dalam iringan musik Barongan Kudus terdiri dari 8 yaitu kendhang ciblon atau bapang, demung, gong suwuk, kempul nada 5 atau 6 , kenong nada 5 atau 6 , bonang nada 5 atau 6, dan slompet. Musik slompet merupakan ciri khas dari kesenian Barongan Kudus yang tidak dimiliki oleh kesenian dari lainnya.

1) Iringan Musik Babak Pertama

a. Dalam adegan pertama berupa sajian tari antara tokoh Penthul, Singo Barong, dan Jaran kepang menggunakan iringan Gendhing Ketawang Puspawarna, dan Gendhing Godril. Gendhing Ketawang Puspawarna menciptakan suasana tenang, damai sedangkan Gendhing Godril menciptakan suasana gembira, bahagia.

(Gambar notasi iringan Gendhing Ketawang Puspawarna, dan Gendhing Godril dapat dilihat di Lampiran 3,4)

b. Dalam adegan kedua berupa sajian tari antara tokoh Penthul dan Singo Barong yang menggunakan Gendhing Bendrong, Gendhing Reogan, dan Gendhing Sampak Slompet. Gedhing Reogan dan Gendhing Bedrong yang menciptakan suasan tegang sedangkan Gendhing Sampak Slompet menciptakan ketegangan karena peperangan. Gendhing tersebut tidak menggunakan notasi dan hanya mengandalkan perasaan penabuh yang sudah ahli atau terbiasa memainkan, sedangkan Gendhing Bendrong memiliki notasi dibandingakn kedua gendhing tersebut. (Gambar notasi iringan Gendhing Bendrong dapat dilihat di Lampiran 5).

c. Dalam adegan ketiga merupakan bagian terakhir pada babak pertama yang berupa penyajian tari jarang kepang yang menggunakan iringan musik Gendhing Rujak Jeruk dan Gendhing Bendrong. Pada Gendhing Rujak Jeruk menciptakan suasana gembira dan bahagia sedangkan Gendhing Bendrong menciptakan suasana ketenangan. (Gambar notasi iringan Gendhing Rujak Jeruk dapat dilihat di Lampiran 6). 


\section{2) Iringan Musik Babak Kedua}

Babak Kedua merupaka sajian tari yang berupa cerita seni Barongan yang berupa cerita Jawa yang menyerupai kethoprak. Dalam sajian tersebut terdapat dialog yang memunculkan peperangan atau pertikaian antar tokoh seni Barongan dan terjadinya konflik yang meningkat.

Adegan dialog antar tokoh Penthul dengan Tembem biasanya berisi tentang lawakan atau lelucon, nasihat-nasihat atau penerangan kepada masyarakat sekitar yang biasanya diselingi dengan lagu dangdut atau pop zaman sekarang yang sudah dilaraskan dengan musik gendhing.

Adegan peperangan yaitu peperangan antara Bondet melawan Celeng, Bondet dan Celeng melawan Singo Barong, Singo Barong melawan Gendarwa, Penthul melawan Singo Barong. Iringan yang digunakan adalah Gendhing Bendrong dan Gendhing Slepeg, Gendhing Bendong dan Gendhing Slepeng menciptakan suasana ketegangan. (Gambar notasi iringan Gendhing Slepeg dapat dilihat di Lampiran 7).

3) Iringan Musik Babak Ketiga

Babak ketiga merupakan babak terakhir dari seni Barongan yang berupa atraksi magis yang menggunakan iringan Gendhing Reogan. Gendhing reogan merupakan gendhing permainan bonang nada 5 dan 6 , kempul, dan slompet (terompet Barongan), gendhing tidak memiliki notasi hanya mengandalkan keahlian dari penabuhnya.

\section{h. Pola Lantai}

Dalam pementasan seni Barongan, pengolahan pola lantai dan pengolahan ruang tidak diperlukan penggarapan secara cermat mengingatgerak-gerak padakesenian Barongan bersifat improvisasif.Pola lantai kesenian Barongan membetuk lurus dan melingkar agar mempermudah proses pergantian gerakan

1. Babak Pertama, pola lantai ini terjadi antara tokoh Penthul, pemain jaran kepang, dan Singo Barong.

\section{a. Pola Lantai Lurus}

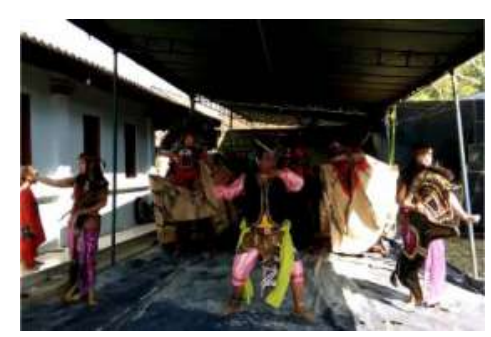

Gambar 19. Pola Lantai Lurus (Foto: Dinda, 2018)

Pola lantai ini pemain jaran kepang menghimpit tokoh Penthul sedangkan Singo Barong berada di belakang. Pola lantai ini membentuk lurus menghadap depan.

b. Pola Lantai Lingkaran

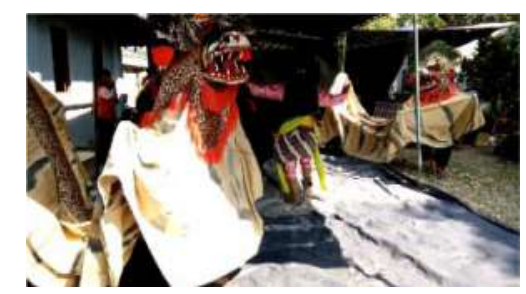

Gambar 20. Pola Lantai Lingkaran (Foto: Dinda, 2018)

Pola lantai ini membentuk lingkaran, posisi Penthul berada di tengah Singo Barong. Posisi menantakan akan terjadi peperangan antara Penthul dengan Singo Barong.

\section{c. Pola Lantai Berhadapan}

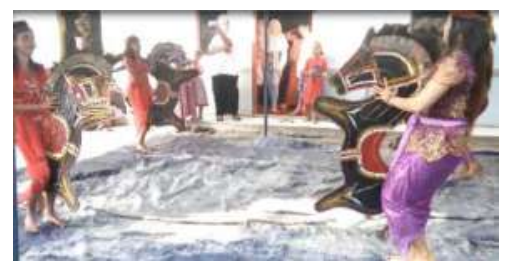

Gambar 21. Pola Lantai Berhadapan (Foto: Dinda, 2018)

Pola lantai ini membentuk berhadapan, posisi penari jaran kepang saling berhadapan dan dimulai untuk melakukan antara penari jaran kepang. 
5. Bentuk Pelestarian

Dalam bentuk pelestarian kesenian Barongan Setyo Budoyo di Desa Loram Wetan, perlu dilakukan langkah-langkah inovatif sebagai berikut:

1) Menyajikan kesenian Barongan Setyo Budoyo di Desa Loram Wetan menjadi sebuah tampilan kesenian yang memikat masyarakat, namun efisien waktu dalam pementasannya.

2) Mendatangkan bintang tamu dalam pementasan kesenian Barongan Setyo Budoyo agar lebih berdaya jual dan menarik pengunjung.

3) Penerapkan manajemen profesional dalam pementasan kesenian Barongan Setyo Budoyo dan mendatangkan generasi penerus.

4) Adanya langkah-langkah sistematis dan terprogram dalam melakukan proses pewarisan nilai-nilai leluhur kesenian Barongan kepada generasi penerus baik melalui kelompok kesenian Barongan Setyo Budoyo maupun lembaga Pendidikan (sekolah).

5) Adanya kerja sama antara Dinas Pariwisata dan Kebudayaan dengan komunitas seni pertunjukan Kesenian Barongansebagai bentuk pelestarian dan pewarisan seni budaya tradisi.

6) Menjadi lebih aktif mengikuti pementasan pada event-event dalam setiap tahun.

\section{KESIMPULAN}

Kesimpulan dalam penelitian ini adalah sebagai berikut

1. Sejarah kesenian Barongan Kudus yang diambil dari cerita babat tanah Jawa

2. Bentuk penyajian Kesenian Barongan Setyo Budoyo yaitu gerak, tata rias, tata busana, tempat pementasan/pertunjukan, properti, iringan musik
3. Bentuk pelestarian Kesenian Barongan yaitu melestarikan kesenian barongan yang dibutuhkan adanya kerjasama anatara pelaku kesenian dengan pemerintah terkait untuk melestarikan kesenian barongan Setyo Budoyo yang hampir punah.

\section{DAFTAR PUSTAKA}

Abidin, Zainal. 2007. Analisis Eksistensial: Sebuah Pendekatan Alternatif untuk Psikologi dan Psikiatri. Jakarta: PT. Raja Grafindo Persada

Gunawan, Imam. 2014. Metode Penelitian Kualitatif: Teori dan Praktik. Jakarta: Bumi Aksara

Jazuli. 1994. Telaah Teoritik Seni Tari. Semarang: IKIP Semarang Press

Jazuli. 1994. Dimensi-Dimensi Tari (Sebuah Kumpulan Karangan). Semarang: IKIP Semarang Press

Jazuli.. 2008. Paradigma Kontekstual Pendidikan Seni. Semarang: Unesa University Press

Kusmayanti, Hermien. 2000. "Arak-arakan" Seni Pertunjukan dalam Upacara Tradisional di Madura. Yogyakarta: Tarawang Press

Langer, Susan K. 1988. Problematika Seni. Bandung: ASTI

Sedyawati, Edi. 1981. Pertumbuhan Seni Pertunjukan. Jakarta: Sinar Harapan

Soedarsono. 1978. Diktat Pengantar Pengetahuan dan Komposisi Tari. Yogyakarta: ASTI

Sugiyono. 2009. Metode Penelitian Kualitatif, Kualitatif dan $R \& D$. Bandung: Alfabeta

Sumono, S. Dwidjo. 1993. Seni Barongan Khas Kudus. Laporan Hasil Observasi Seksi Kebudayaan Depdikbud Kabupaten Kudus 